\title{
Long term outcome after 48 Gy stereotactic ablative body radiotherapy for peripheral stage I non-small cell lung cancer
}

Emilie Dubaere ${ }^{1}$, Mathilde Goffaux ${ }^{2}$, Marie Wanet ${ }^{1}$, Benoit Bihin $^{2,3}$, Céline Gheldof ${ }^{1}$, Anne-Sophie Demoulin ${ }^{4}$, Antoine Bolly ${ }^{1}$, Frederique Bustin ${ }^{4}$, Fabrice Duplaquet ${ }^{3}$, Paul-Emile Baugnee ${ }^{5}$, Michel Gustin ${ }^{4}$, Vincent Hers ${ }^{5}$, Fabienne Maisin ${ }^{1}$, Eric Marchand ${ }^{2,3}$, Sebahat Ocak ${ }^{3,8}$, Lionel Pirard ${ }^{3}$, Oswald Vancutsem ${ }^{6}$, Evelyne Van Neck Guy Vandermoten ${ }^{5}$, Luminata Zaharia $^{5}$ and Vincent Remouchamps ${ }^{1,2^{*}}$

\begin{abstract}
Background: To evaluate the outcome of patients treated with stereotactic ablative body radiotherapy (SABR) with curative intent for stage I non-small cell lung cancer (NSCLC) with regard to local, regional and distant tumor control, disease-free survival (DFS), overall survival (OS) and toxicity.

Methods: Data of 300 patients treated with SABR for NSCLC cancer for the period of November 2007 to June 2016 were retrospectively analyzed. Of which, 189 patients had single primary lung lesion and were included in the study. The prescribed dose for the tumor was $48 \mathrm{~Gy}$, given in $12 \mathrm{~Gy} \times 4$ fractions for all patients. In 2010, an improved protocol was established in advanced technology for the planning $C T$, dose calculation and imaging. Cumulative incidence function (CIF) of local, regional, distant or any recurrences were computed using competing risk analysis with death as a competing event. Survivals (DFS and OS) were estimated using the Kaplan-Meier method and Cox proportional regression was used for comparisons. Toxicities were graded according to the common terminology criteria for adverse events version 4.0 (CTCAE v.4).

Results: Diagnosis was histologically confirmed in $42 \%$ of the patients $(N=80)$. At 1,2 and 4 years, the cumulative incidence function (CIF) of local relapses were $8 \%$ [4-13\%], 15\% [10-21\%] and 18\% [12-25\%], the CIF of regional relapses were $4 \%$ [2-8\%], 10\% [6-16\%] and 12\% [8-19\%], the CIF of distant relapses were 9\% [5-14\%], 15\% [11-22\%] and 20\% [15-28\%] and the CIF of any relapses were 14\% [10-20\%], 28\% [22-36\%], 34\% [27-43\%], respectively. After 1 , 2 and 4 years, the OS rates were 83\% [95\% Cl: $78-89 \%](N=128), 65 \%$ [95\% Cl: 57-73\%] $(N=78)$ and 37\% [95\% Cl: 29-47\%] ( $N=53)$, respectively. The median survival time was 37 months. The DFS after 1, 2 and 4 years reached $75 \%$ [95\% Cl: 68-81\%] ( $N=114), 49 \%$ [95\% Cl: 42-58\%] $(N=60)$ and 31\% [95\% Cl: 24-41\%] $(N=41)$, respectively. No grade 4 or 5 toxicity was observed.
\end{abstract}

Conclusions: We observed a long-term local control and survival after SABR for peripheral stage I NSCLC in this large series of patients with the expected low toxicity.

Keywords: Stereotactic ablative radiotherapy, Lung cancer, Non-small cell lung cancer, Survival

\footnotetext{
* Correspondence: vincent.remouchamps@uclouvain.be

Partially presented as posters at the 2010, 2012, 2014 and 2018 meetings of

the European Society of Therapeutic Radiation Oncology (ESTRO).

${ }^{1}$ Department of Radiotherapy, CHU UCL Namur, Site Ste Elisabeth, Place

Louise Godin 15, 5000 Namur, Belgium

${ }^{2}$ NARILIS, Namur, Belgium

Full list of author information is available at the end of the article
}

(c) The Author(s). 2019 Open Access This article is distributed under the terms of the Creative Commons Attribution 4.0 International License (http://creativecommons.org/licenses/by/4.0/), which permits unrestricted use, distribution, and reproduction in any medium, provided you give appropriate credit to the original author(s) and the source, provide a link to the Creative Commons license, and indicate if changes were made. The Creative Commons Public Domain Dedication waiver (http://creativecommons.org/publicdomain/zero/1.0/) applies to the data made available in this article, unless otherwise stated. 


\section{Background}

The standard treatment for stage I non-small cell lung cancer (NSCLC) is surgery, with excellent local control and survival outcome $[1,2]$. However, a substantial proportion of patients are unfit to tolerate any type of surgical resection due to their comorbidities. Furthermore, a small proportion of patients rejected the option of surgery based on personal reasons. The alternative treatment for these patients was no treatment at all or primary conventional radiotherapy with a total dose of 60 to 70 Gy in fractions of 2 Gy a day [3]. The outcome after conventional radiotherapy has been relatively poor, with a long term survival of $15-30 \%$ and local control only being $40-50 \%[4,5]$. Due to advances in radiation modalities, the management upgraded to stereotactic ablative body radiotherapy (SABR). Better local control may be reached by increasing radiation therapy dose, resulting in better overall survival (OS) [6]. SABR is a radiation technique which assigns a high radiation dose with precise delivery and high conformity while avoiding radiosensitive organs surrounding the tumor. In comparison to conventional radiotherapy, which is delivered over several weeks, SABR is typically administered in few fractions, typically 3 to 10 fractions, reducing the overall treatment time. In addition, the toxicity profile of this non-invasive treatment is quite favorable [7, 8]. An excellent clinical outcome with SABR has been observed with several studies showing comparable results to those obtained through surgery. Local control rates are approximately 80 to $90 \%$ when schedules with biologically effective dose (BED) larger than 100 Gy are used [9-12].

We retrospectively evaluated the local, regional and distant tumor control, as well as the disease-free survival (DFS), OS and toxicity in our unselected patient population that was treated over the last 10 years. In recent years, there have been advances in the radiotherapy techniques, delivery for SABR and treatment methods in our department, however, the $12 \mathrm{~Gy} \times 4$ fractions prescription has remained unaltered.

\section{Methods}

\section{Patient population}

Data of 300 patients with stage I NSCLC (American Joint Committee on Cancer, seventh edition T1a T1bT2 N0 M0) [13] treated for peripheral lung lesions with a standard SABR protocol between November 2007 and June 2016 were retrospectively reviewed. The review was approved by the Institutional Review Board under the current legislation (Ethics Committee from CHU UCL Namur, site Ste. Elisabeth and its President, Dr. Isabelle Mathieu). The acceptance date of the ethics committee was 21 October 2016. Patients with central lesions, multiple nodules, metastatic lung lesions or synchronous cancers were excluded. Also, patients were recruited from several institutions but treated in a single radiation therapy department. In-hospital medical files and letters from the referring pneumologist or oncologist for patients followed-up on in collaborating institutions were reviewed.

An experienced multidisciplinary team carefully studied patient's characteristics (i.e. smoking history and age) and their images before suggesting treatment without histological confirmation. There was a need for an adequate record of the growth of the tumor size over time, a high ${ }^{18}$ F-FDG-PET uptake and morphological abnormalities suggestive of malignancy [14, 15].

When follow-up is lost, which usually happens after supportive care, the vital status was obtained after phone calls to the family or general practitioners.

\section{Procedures}

\section{Image acquisition}

All patients underwent fluoro-deoxy-glucose positron emission tomography and computed tomography (FDGPET-CT) for staging, usually contrast-enhanced. All patients underwent planning $\mathrm{CT}$ with a slice thickness of $2.5 \mathrm{~mm}$ and a four-dimensional (4D)-CT on a dedicated CT simulator (General Electric RT16, General Electric Company, Boston). Two different 4D image acquisition procedures were used according to the date of patient inclusion in the study. Initially, a 3 phase CT including a physiological inspiration, expiration and free breathing were performed. From the end of 2009, a 10 phase 4DCT using the Real-time Position Management (RPM ${ }^{\circ}$, Varian Medical Systems, Palo Alto, CA, USA) device was used. Patients were immobilized with a thermoplastic mask. In 2010, the diaphragmatic compression was added. Images were transferred to the Eclipse planning system (TPS; Eclipse version 8 to 11 during this period, Varian Medical Systems, Palo Alto, CA, USA).

\section{Organs at risk and volumes delineation}

The gross tumor volume (GTV) included the visible tumor, delineated with a lung windowing setting (level 600 Hounsfield Unit (HU); width $1600 \mathrm{HU}$ ). An internal target volume (ITV) encompassing all tumor position in the breathing cycle was delineated using all phases of the 4D-CT. No clinical target volume (CTV) margins were used. An isotropic margin of $5 \mathrm{~mm}$ around the ITV was used to create the setup margin component of planning target volume (PTV).

The organs at risk (OARs), that is, the spinal cord, lungs, heart, great vessels, proximal bronchi, brachial plexus, chest wall, trachea, esophagus and skin, were delineated depending on the location of the tumor. According to reports 62 and 83 of the International Commission on Radiation Units and measurements, a safe $5 \mathrm{~mm}$ margin was added to the spinal cord as 
planning at risk volume (PRV). Adding a PRV for the esophagus or 4D delineation according to the location of the target was hardly necessary as they were all peripheral lesions.

\section{Treatment planning}

For all patients, the total prescribed dose to the PTV was $48 \mathrm{~Gy}$ in $12 \mathrm{~Gy} \times 4$ fractions. Treatments were administered on a linear accelerator (Clinac ${ }^{\circ}$ 21EX; Varian Medical Systems, Palo Alto, CA, USA and Novalis TX; Varian Medical Systems, Palo Alto, CA, USA) delivering $6 \mathrm{MV}$ photons. Dose constraints for OARs and target volumes (TVs) were compliant with the national protocol derived from RTOG trial 0915. From 2007 to 2010, most patients were treated with multiple (minimum of seven) coplanar and/or non-coplanar beams with threedimensional conventional radiotherapy (3D-CRT) using pencil beam dose calculation algorithm (Type I dose computation algorithm). Twenty five percent of patients from the period before 2010 with limited breathing motion (less than $5 \mathrm{~mm}$ ) on inspiration and expiration CT were treated on the Tomotherapy unit, while the others were treated on a $5 \mathrm{~mm}$ leaves Millenium multi-leaf collimator (MLC) linear accelerator. The total dose was prescribed at the isocenter, accepting $80-95 \%$ around the PTV [16]. Fractions were delivered every other day. On the Tomotherapy system, a type II calculation algorithm was used. From 2010, all patients were treated with volumetric modulated arc therapy (VMAT) with the Varian method named Rapidarc on a Novalis Tx linear accelerator using an analytic anisotropic algorithm (AAA) calculation for treatment planning (Type II dose computation algorithm) and a $2.5 \mathrm{~mm}$ leaves MLC. Two half arcs with different collimation angles were used to avoid interplay effect. The dose was prescribed to $80 \%$ isodose encompassing the PTV (48 Gy isodose around the PTV), with an aimed dose inhomogeneity allowing a $100 \%$ maximum dose in the GTV, corresponding to a $25 \%$ over dosage located in the GTV. This method was copied from the RTOG protocols. The later release of the ICRU report 91 confirmed these evolutions [17]. Beginning from 2010, fractions were allowed once a day with a $48 \mathrm{~h}$ break in the middle of the week, but most patients were treated with two to three fractions a week for logistic reasons.

\section{Setup and delivery procedures}

Initially, verification of patient setup and tumor position was performed daily using orthogonal Mega Voltage (MV) portal images with online correction and additional 2D-real time cine-acquisition images. On these images, the tumor and its motion could be seen in the Beam Eye View of some beam angles for most patients. Patients in this period treated on the
Tomotherapy machine were positioned with on-line volumetric MV CT imaging before and during the fraction. Systematic volumetric Cone-Beam Computed Tomography $(\mathrm{CBCT})$ came into the scene in 2010. It was performed before the start of the session and with a second $\mathrm{CBCT}$ in between two arcs in order to verify the intra-fraction stability.

\section{Toxicity}

Radiation-induced toxicities were evaluated according to the Common Terminology Criteria for Adverse Events (CTCAE) version 4.0.

\section{Follow-up}

First clinical and radiological follow-up is usually done 3 months after the completion of radiotherapy and subsequently, every 6 months. Clinical examination and chest CT with complementary FDG-PET-CT in case of uncertain recurrence were performed.

Local, regional and distant recurrences were censored. Local recurrence includes a failure within or adjacent to the PTV. Local control was defined as the absence of local progression. The distinction from recurrence or benign lung fibrosis has constantly been difficult. Suspicious images were considered as local relapses without central review. Histological confirmation was not a prerequisite for classifying the lesion as recurrence. Differentiation between benign radiographic changes and local recurrence after SABR remains challenging because many patients developed radiation-induced fibrosis in the treated lung region $[18,19]$. Therefore, it is likely that some local relapses were actually radiationinduced fibrosis. Regional recurrence was defined as a failure in the hilum, mediastinum or supraclavicular fossae while distant recurrence as a failure in other sites.

\section{Statistical analysis}

Median follow-up was assessed by the reverse Kaplan-Meier method. OS was defined from the start of radiotherapy to death by any cause. DFS was assessed from the start of radiotherapy until death or local, regional or distant relapse. OS and DFS were computed with Kaplan-Meier method. Cumulative incidence function (CIF) of local, regional, distant or any recurrences were computed using competing risk analysis with death as a competing event.

Exploratory subgroup analyses were performed comparatively on OS, DFS and relapses according to 3 factors: treatment period (before 2010 versus after 2010), previous (if any) cancer history (presence versus absence), and tumor stage ( $\mathrm{T} 1 \mathrm{a}$ versus $\mathrm{T} 1 \mathrm{~b}$ and $\mathrm{T} 1 \mathrm{a}$ versus T2). Cox proportional hazards regression models were used to assess the association between OS and DFS rates and these variables. Fine and Gray's proportional 
subdistribution hazards regression models and Cox proportional cause-specific hazards models were used to estimate the subdistribution hazard ratios (sHR) and the cause-specific hazard ratios (csHR) respectively.

The $\mathrm{R}$ software version 3.3.2 (The $\mathrm{R}$ Foundation for Statistical Computing, Vienna, 2016) was used for statistical analyses with the following packages: ggplot2, survival and survminer.

\section{Results}

\section{Patient characteristics}

One hundred and eighty-nine patients treated with SABR for a single primary lung lesion and also treated with a 12 Gy $\times 4$ fractions scheme were analyzed in this retrospective analysis.

The median age was $72 \pm 9,8$ (range: $46-89$ years), $66 \%$ were men, $93 \%$ were smokers or ex-smokers. Diagnosis was histologically confirmed in $42 \%$ of the patients $(N=80)$, including $21 \%(N=39)$ lung adenocarcinoma, $15 \%(N=29)$ lung squamous cell carcinoma and 6\% $(N=12)$ not otherwise specified NSCLC. The remaining 109 patients were treated without histological confirmation (58\%) due to a contraindication for a transthoracic biopsy (e.g. severe COPD status in most of the cases).

The median tumor diameter was $18 \mathrm{~mm} \pm 7,8$ (range 6-37 mm). Tumors were located in the right lung in $54 \%$ of the patients $(N=102)$, including $32 \%(N=61)$ in the upper lobe, $5 \%(N=9)$ in the middle lobe and $17 \%$ $(N=32)$ in the inferior lobe. Tumors were located in the left lung in the upper and lower lobes in $29 \%(N=55)$ and $17 \%(\mathrm{~N}=32)$ of the patients, respectively.

AJCC 7 TNM stage distribution was; T1a: 59\% $(N=111), \mathrm{T} 1 \mathrm{~b}: 30 \%(N=57), \mathrm{T} 2: 11 \%(N=21)$; all patients were N0 and M0.

There were 411 listed contraindications for 189 patients. The most important contraindications to surgery were pulmonary $(N=137$ and $72 \%)$ and/or cardiac disfunctions $(N=80$ and $42 \%)$. Only 15 patients $(8 \%)$ refused surgery.

Treatment and patient's characteristics are shown in Table 1.

\section{Overall analysis}

The median follow-up of surviving patients is 18 months +/- 21 (interquartile range: 9-33 months).

\section{Survival}

After 1, 2 and 4 years, the OS rates [95\% confidence interval] were 83\% [78-89\%] $(N=128), 65 \%$ [57-73\%] $(N=78)$ and $37 \%$ [29-47\%] $(N=53)$, respectively. The median survival time was 37 months. DFS rates were 75\% [95\% CI: $68-81 \%$ ] $(N=114), 49 \%$ [95\% CI: 42-58\%]
Table 1 Patient characteristics

\begin{tabular}{ll}
\hline Number of patients $(\mathrm{N})$ & 189 \\
\hline Male/female & $66 \%(\mathrm{~N}=124) / 34 \%(\mathrm{~N}=65)$ \\
Age (median and range) & $72 \pm 9,8(46-89$ years $)$ \\
T-stage T1a & $59 \%(\mathrm{~N}=111)$ \\
T1b & $30 \%(\mathrm{~N}=57)$ \\
T2 & $11 \%(\mathrm{~N}=21)$ \\
Tumor size (median and range) & $18 \mathrm{~mm} \pm 7,8(6-37 \mathrm{~mm})$ \\
Histology Unknown & $58 \%(\mathrm{~N}=109)$ \\
$\quad$ Known ADK & $21 \%(\mathrm{~N}=39)$ \\
$\quad$ SCC & $15 \%(\mathrm{~N}=29)$ \\
$\quad$ NOS & $6 \%(\mathrm{~N}=12)$ \\
Right Lung & $54 \%(\mathrm{~N}=102)$ \\
$\quad$ Upper lobe & $32 \%(\mathrm{~N}=61)$ \\
Middle lobe & $5 \%(\mathrm{~N}=9)$ \\
Inferior lobe & $17 \%(\mathrm{~N}=32)$ \\
Left lung & $46 \%(\mathrm{~N}=87)$ \\
Upper lobe & $29 \%(\mathrm{~N}=55)$ \\
Inferior lobe & $17 \%(\mathrm{~N}=32)$ \\
\hline Abbrevations: $A$ aD aden
\end{tabular}

Abbreviations: ADK adenocarcinoma, SCC squamous cell carcinoma, NOS not otherwise specified

$(N=60)$ and $31 \%$ [95\% CI: $24-41 \%](N=41)$ after 1,2 and 4 years, respectively (Fig. 1a and b).

\section{Failure patterns}

Overall, we observed 27 patients with local relapses (14\%), 18 with regional relapses (10\%), 29 with distant relapses (15\%) and 51 with at least one relapse (27\%).

At 1, 2 and 4 years, the cumulative incidence function (CIF) of local relapses were $8 \%$ [4-13\%], 15\% [10-21\%] and $18 \%$ [12-25\%], the CIF of regional relapses were $4 \%$ [2-8\%], 10\% [6-16\%] and $12 \%$ [8-19\%], the CIF of distant relapses were 9\% [5-14\%], 15\% [11-22\%] and $20 \%[15-28 \%]$ and the CIF of any relapses were $14 \%$ [10-20\%], 28\% [22-36\%], 34\% [27-43\%], respectively (Fig. 2).

One patient was reclassified as locally controlled after a salvage surgery that demonstrated the absence of residual disease.

\section{Subgroup analysis}

Stage T1b (vs T1a) was associated with a worse OS (univariate HR (uHR): 1.49, multivariate HR (mHR): 1.66, 95\% confidence interval (CI): [1.06-2.59], $p=$ 0.026 ) and a worse DFS (uHR: 1.43 , mHR: $1.57,95 \% \mathrm{CI}$ : [1.02-2.41], $p=0.038$ ). Treatment period and previous cancer history were not found to be significantly associated with OS nor DFS.

Treatment period was associated with a decrease of incidence of any recurrences (univariate sHR (usHR): 0.42, 


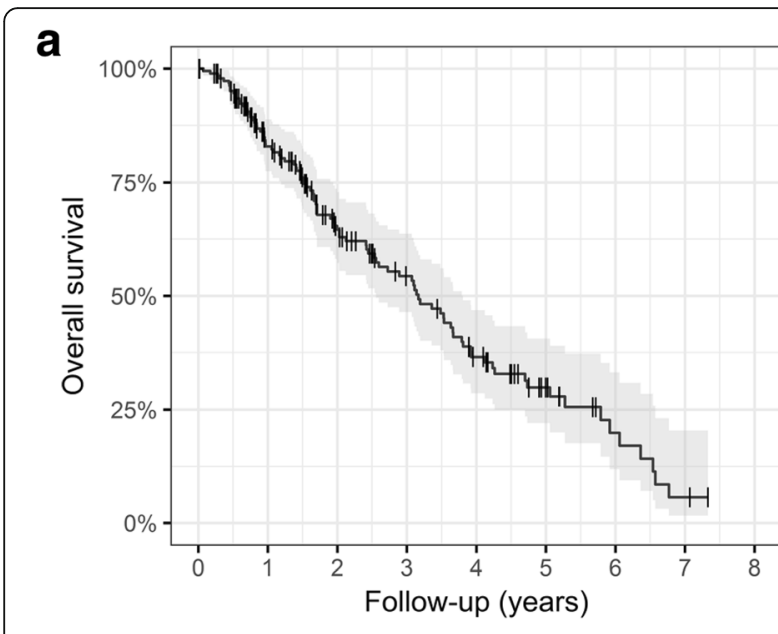

Number at risk
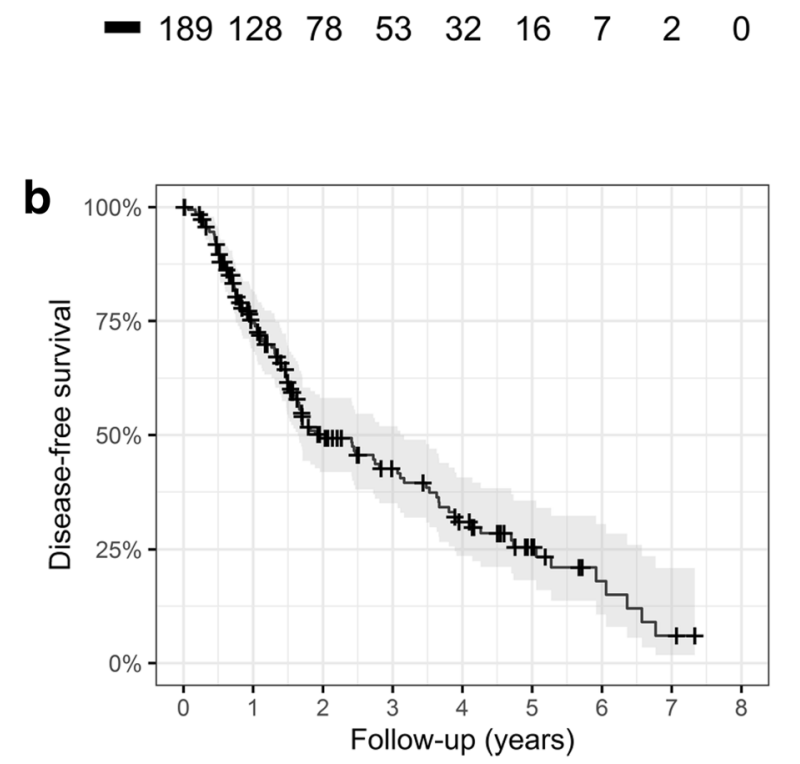

Number at risk

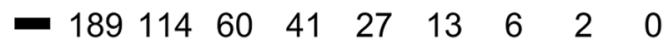

Fig. 1 a Overall survival (OS) b Disease-free survival (DFS)

multivariate $\mathrm{sHR}$ (msHR): 0.49 [0.29-0.90], $\mathrm{p}=0.02$ ). The association between treatment period and local relapses was slight but inconclusive (usHR: 0.43, msHR: 0.47 [0.21-1.06], $p=0.07$ ).

Previous cancer history was associated with an increase of distant relapses (usHR: 3.28 , msHR: 3.33 [1.34-8.27], $p=0.01)$. Stage T1b was not associated with incidence of local, regional or distant relapses.

\section{Toxicity}

For all patients, grade 1 to 3 toxicities were: fatigue (41\%; $N=77)$, chest wall pain $(10 \% ; N=19)$, dyspnea $(7 \% ; N=14)$, radiation pneumonitis $(4 \% ; N=8$, including $2 \%$ of grade 3$)$, dermatitis $(4 \% ; \mathrm{N}=7)$, cough $(3 \% ; N=6)$, rib fractures $(2 \% ; N=3)$, and esophagitis $(1 \% ; \mathrm{N}=1)$. No grade 4 or 5 toxicity was observed.

\section{Discussion}

This cohort of 189 frail patients covers a decade of early-stage NSCLC patients treated with SABR in a single radiation oncology department with a median follow-up of 18 months. The 2 and 4-year OS and DFS rates reached 65 and 37\%, respectively and 49 and 31\%, respectively. At 2 and 4 years, the cumulative incidence function (CIF) of local relapses, regional relapses and distant relapses were 15 and 18\%, 10 and $12 \%, 15$ and $20 \%$, respectively. The CIF of any relapses at 2 and 4 years were 28 and 34\%, respectively. Our results in terms of clinical outcomes are comparatively similar to recently published data. In a recent review of 72 SABR studies, Chi et al. reported a 5 -year OS rate of $41.3 \%$ after SABR [11].

Regarding toxicities, our data are also coherent with the recent review of Chi et al. with a low incidence of grade 3 radiation pneumonitis and the overall incidence of rib fractures. The incidence of grade 3 radiation pneumonitis was $2 \%$ compared to $3.4 \%$ in Chi et al. and the incidence of rib fractures for our study against Chi et al. was $2 \%$ vs. $3.2 \%$.

The main limitation of our study is its retrospective nature, although all the patients are treated at a single radiation center after referrals from several hospitals.

A second limitation is the absence of a central review of follow-up imaging. However, most follow-up images were reviewed in the local multidisciplinary thoracic oncology board of the patient's hospital, including a radiologist and/or a nuclear physician. All suspected lesions were counted as local relapses, which can be seen as another limitation with an under-estimated local control. Histological confirmation was not a prerequisite for classifying lesions as recurrence. Differentiation between benign radiographic changes and local recurrence after SABR remains a challenge as many patients developed radiation-induced fibrosis in the treated lung region [18, 19]. Therefore, it is likely that some local relapses were actually radiation-induced fibrosis.

Patients treated without histological confirmation had to meet the following criteria: an increase in tumor size over time, a high FDG-PET uptake and morphological abnormalities suggestive of malignancy. When all these criteria are fulfilled and there were no signs of infection, the probability of benign diagnosis is less than $4 \%[14,15]$. The recent American Society for Radiation Oncology (ASTRO) guideline acknowledges the concept of treating with SABR without histology in this context [20]. A high proportion of patients in our series were treated without histological confirmation (58\%). This may indicate a high proportion of 


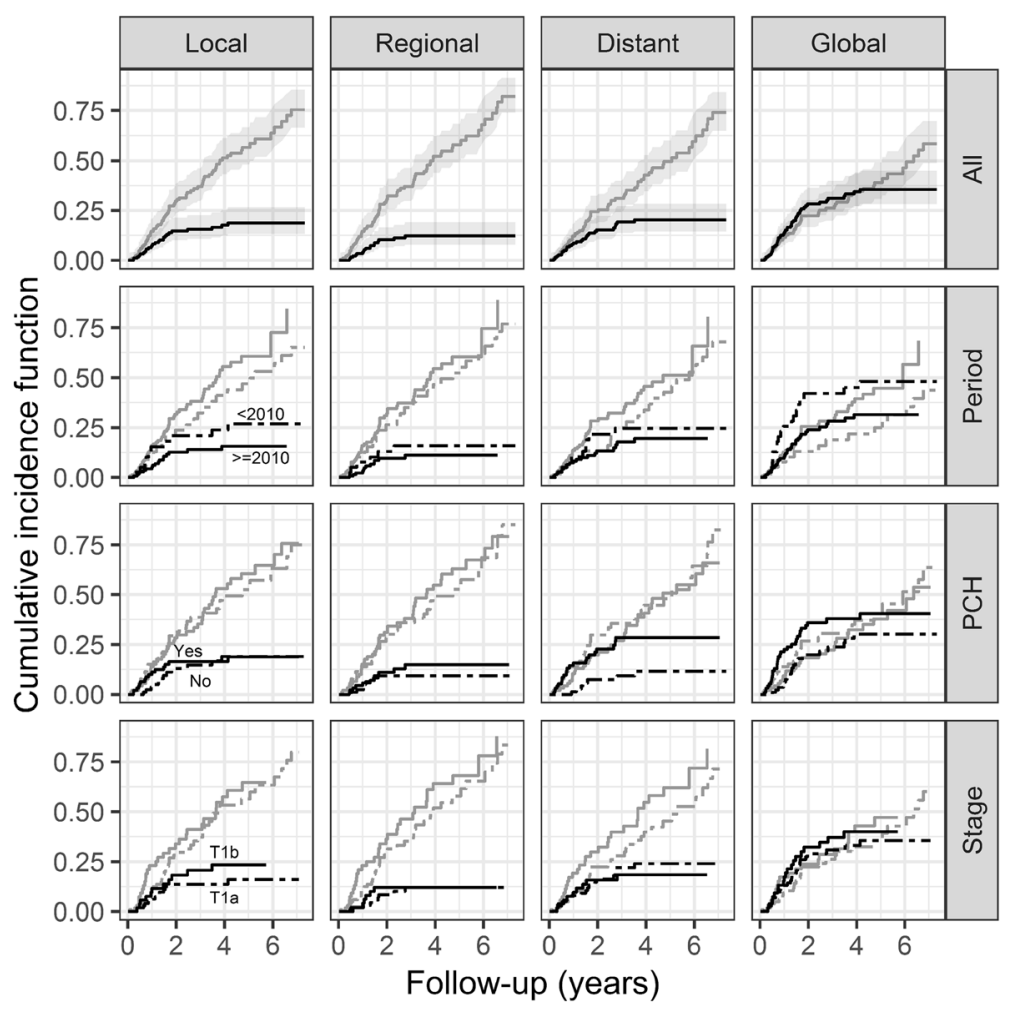

Fig. 2 Cumulative incidence function (CIF) of local, regional, distant or any relapses. CIF of relapses and death are represented in black and grey respectively. CIF are presented for the whole group (All), in two groups following the period (before 2010 and after 2010), the existence of a previous cancer history (PCH) and tumor stage (T1a versus T1b, stage $\mathrm{T} 2$ is not shown)

frail patients in our population with a contraindication for a transthoracic biopsy.

As compared to the recent international Advisory Committee on Radiation Oncology Practice (ACROP) recommendations, our methods especially since 2010, are in tandem in terms of the radiation preparation, prescription methods, delivery, and technologies [21]. One difference with our group of patients is the recommendation of more frequent use of post-therapeutic biopsies if a relapse is suspected for patients eligible for salvage treatments. This was not the current practice in our patient series, as $58 \%$ were already considered ineligible for a transthoracic biopsy during the initial diagnosis. Another major difference with these recommendations is the radiation dose. Our $12 \mathrm{~Gy} \times 4$ fractions schema corresponds to a BED with an alpha/beta of 10 in the linear quadratic model (BED 10) of $106 \mathrm{~Gy}$, superior to the favorable $100 \mathrm{~Gy}$ threshold. The ACROP consensus proposed to keep the $12 \mathrm{~Gy} \times 4$ fractions schema for tumors with a substantial contact with the chest wall, or an adapted $15 \mathrm{~Gy} \times 3$ fractions escalated schema (BED $113 \mathrm{~Gy}$ ), and for the best prognosis patients, a much higher dose of $18 \mathrm{~Gy} \times 3$ fractions. Considering our slightly lower than expected local control $(74 \%$ for the whole patient cohort at the median follow-up of 4 years and 1 year), our prescriptions nowadays are sometimes adapted in accordance to ACROP recommendation (18 Gy $\times 3$ fractions) depending on the clinical situation and when a higher dose can safely be delivered.

The substantial technological advancements during the recruitment of patients can be viewed as another methodological weakness, although they represent reallife practice. The patients were treated with a nominally constant dose prescription. However, considering the fact that the dose was first prescribed at the isocenter using a pencil beam algorithm, and later at the isodose encompassing the PTV using an AAA algorithm, proved a significant dose escalation by at least $25 \%$. The studied outcome parameters were not clearly improved by the new technologies or with the derived prescription method, but we remark a slight association between the treatment period and the incidence of any recurrences. However, the decrease in relapses is concomitant with an increase of deaths. The positive impact of the treatment period must therefore be further demonstrated. The limitations of this non-randomized comparison highlights the difficulties in radiation oncology to assess the potential clinical improvement of new technologies, as illustrated by Chi et al. when trying to compare SABR with hypo-fractionated particle beam therapy [11]. 
Typically, the financial investment for the new radiotherapy machine and methods (dose computation, arc delivery, volumetric image guidance methods, full breathing cycle gating) were performed in 2010, while the improved clinical outcome (improved local control) was only hypothesized in our 2017 review and is not even confirmed.

\section{Conclusion}

We observed a long-term local control and survival after SABR for peripheral stage I NSCLC in this large series of patients with the expected low toxicity.

\begin{abstract}
Abbreviations
4D-CT: a four-dimensional computed tomography; AAA: analytic anisotropic algorithm; ACROP: Advisory Committee on Radiation Oncology Practice; ADK: Adenocarcinoma; ASTRO: American Society for Radiation Oncology: BED: Biologically effective dose; CBCT: Cone-Beam Computed Tomography; CTCAE: Common Terminology Criteria for Adverse Events; CTV: Clinical target volume; FDG-PET-CT: fluoro-deoxy-glucose positron emission computed tomography; GTV: Gross tumor volume; HU: Hounsfield Unit; ITV: Internal target volume; MLC: Multi-leaf collimator; MV: Mega Voltage; NOS: Not otherwise specified; NSCLC: Non-small cell lung cancer; OAR: Organs at risk; OS: Overall survival; PCH: Previous cancer history; PRV: Planning at risk volume; PTV: Planning target volume; RFS: Relapse-free survival; RPM: Realtime Position Management; SABR: Stereotactic ablative body radiotherapy; SCC: Squamous cell carcinoma; TVs: Target volumes; VMAT: Volumetric modulated arc therapy; VMS: Varian Medical Systems
\end{abstract}

\section{Acknowledgments}

We thank the patients and the multidisciplinary team involved in these treatments performed during the 10-year period.

\section{Authors' contributions}

ED was the writer of the manuscript. VR was a major contributor in writing the manuscript. ED, MG1 and CG bundled the data. BB analyzed and interpreted the patient data. MW, ASD, AB, FB, FD, PEB, MG2, VH, FM, EM, SO, $L P, O V, E V N, G V, L Z$ and VR treated the patients and collected the data. All authors read and approved the final manuscript.

Summary of the paper presented at 37th ESTRO congress. (Dubaere, E., Goffaux, M., Bihin, B., Gheldof, C., Demoulin, A. S., Bolly, A., ... \& Hers, V. (2018). Long term results and technology impact of 48 Gy SABR for inoperable peripheral stage I lung cancer. Survival, 83(65), 37).

\section{Funding}

None.

\section{Availability of data and materials}

The datasets used and analyzed during the current study are available from the corresponding author on reasonable request

\section{Ethics approval and consent to participate}

The review was approved by the Institutional Review Board under the current legislation (Ethics Committee from CHU UCL Namur, site Ste. Elisabeth and its President, Dr. Isabelle Mathieu). The acceptance date of the ethics committee was 21 October 2016.

An informed consent is not required for this study in this retrospective setting. Approved by Ethics Committee from CHU UCL Namur, site Ste. Elisabeth and its President, Dr. Isabelle Mathieu.

\section{Consent for publication}

Not applicable.

\section{Competing interests}

The authors declare that they have no competing interests.

\section{Author details}

'Department of Radiotherapy, CHU UCL Namur, Site Ste Elisabeth, Place Louise Godin 15, 5000 Namur, Belgium. ${ }^{2}$ NARILIS, Namur, Belgium. ${ }^{3} \mathrm{CHU}$ UCL Namur, Site Godinne, Yvoir, Belgium. ${ }^{4} \mathrm{CHR}$ Citadelle Liege, Liege, Belgium. ${ }^{5} \mathrm{CHR}$ Sambre et Meuse, Namur, Belgium. ${ }^{6} \mathrm{Clinique}$ St Luc Bouge, Namur, Belgium. ${ }^{7} \mathrm{CHU}$ UCL Namur, Site Dinant, Dinant, Belgium. ${ }^{8}$ Institut de Recherche Expérimentale et Clinique (IREC), Pôle de Pneumologie, ORL et Dermatologie (PNEU), Université Catholique de Louvain (UCL), Brussels, Belgium.

Received: 9 January 2019 Accepted: 20 June 2019

Published online: 28 June 2019

\section{References}

1. Ginsberg RJ, Rubinstein LV. Randomized trial of lobectomy versus limited resection for T1 No non-small cell lung cancer. Ann Thorac Surg. 1995;60(3): 615-23 Available from: https://www-sciencedirect-com.kuleuven.ezproxy. kuleuven.be/science/article/pii/000349759500537U.

2. Scott WJ, Howington J, Feigenberg S, Movsas B, Pisters K, American College of Chest Physicians. Treatment of non-small cell lung Cancer stage I and stage II. Chest [Internet]. 2007;132(3):234S-42S Available from: http://www. ncbi.nlm.nih.gov/pubmed/17873171.

3. National Comprehensive Cancer Netwirk. Non-Small Cell Lung Cancer. NCCN Clin Pract Guidel Oncol (NCCN Guidel). 2019; Available from: https:// www.nccn.org/professionals/physician_gls/pdf/nscl.pdf.

4. Timmerman R, Paulus R, Galvin J, Michalski J, Straube W, Bradley J, et al. Stereotactic body radiation therapy for inoperable early stage lung Cancer. JAMA. 2010;303(11):1070 Available from: http://jama.jamanetwork.com/ article.aspx?doi=10.1001/jama.2010.261.

5. Dosoretz DE, Katin MJ, Blitzer PH, Rubenstein JH, Galmarini DH, Garton GR, et al. Medically inoperable lung carcinoma: the role of radiation therapy. Semin Radiat Oncol. 1996;6(2):98-104 Available from: https://wwwsciencedirect-com.kuleuven.ezproxy.kuleuven.be/science/article/pii/ S1053429696800063.

6. Ball D, Mai T, Vinod S, Babington S, Ruben J, Kron T, et al. MA 13.07 A Randomized Trial of SABR vs Conventional Radiotherapy for Inoperable Stage I Non-Small Cell Lung Cancer: TROG09.02 (CHISEL). J Thorac Oncol [Internet]. 2017;12(11):S1853 Available from: http://linkinghub.elsevier.com/ retrieve/pii/S155608641731300X.

7. van der Voort van Zyp NC, Prévost J-B, van der Holt B, Braat C, van Klaveren RJ, Pattynama PM, et al. Quality of life after stereotactic radiotherapy for stage I non-small-cell lung Cancer. Int J Radiat Oncol. 2010;77(1):31-7 Available from: http://www.ncbi.nlm.nih.gov/pubmed/19864077.

8. Senan S, Gundy C, Haasbeek CJ, Slotman BJ, Aaronson NK, Lagerwaard FJ. Health-related quality of life (HRQOL) after stereotactic body radiotherapy (SBRT) for stage I non-small cell lung cancer (NSCLC). J Clin Oncol. 2010; 28(15_suppl):7079 Available from: http://ascopubs.org/doi/10.1200/jco.2010. 28.15 suppl.7079.

9. Nagata Y, Takayama K, Matsuo Y, Norihisa Y, Mizowaki T, Sakamoto T, et al. Clinical outcomes of a phase I/II study of 48 Gy of stereotactic body radiotherapy in 4 fractions for primary lung cancer using a stereotactic body frame. Int J Radiat Oncol Biol Phys. 2005.

10. Lagerwaard FJ, Haasbeek CJA, Smit EF, Slotman BJ, Senan S. Outcomes of risk-adapted fractionated stereotactic radiotherapy for stage I non-small-cell lung Cancer. Int J Radiat Oncol. 2008;70(3):685-92 Available from: https:// www-sciencedirect-com.kuleuven.ezproxy.kuleuven.be/science/article/pii/ S0360301607044689.

11. Chi A, Chen H, Wen S, Yan H, Liao Z. Comparison of particle beam therapy and stereotactic body radiotherapy for early stage non-small cell lung cancer: a systematic review and hypothesis-generating meta-analysis. Radiother Oncol. 2017;123(3):346-54 Available from: https://wwwsciencedirect-com.kuleuven.ezproxy.kuleuven.be/science/article/pii/ S0167814017303717.

12. Timmerman R, McGarry R, Yiannoutsos C, Papiez L, Tudor K, DeLuca J, et al. Excessive toxicity when treating central tumors in a phase II study of stereotactic body radiation therapy for medically inoperable early-stage lung cancer. J Clin Oncol. 2006.

13. Sobin $\mathrm{LH}$, Gospodarowicz MK, Wittekind C. TNM Classification of malignant Tumours. [internet]. Wiley; 2011]. 201 p. Available from: https://www.wiley. com/en-us/TNM+Classification+of+Malignant+Tumours\%2C+7th+Edition-p9781444358964 
14. van Tinteren $\mathrm{H}$, Hoekstra OS, Smit EF, van den Bergh JH, Schreurs AJ, Stallaert RA, et al. Effectiveness of positron emission tomography in the preoperative assessment of patients with suspected non-small-cell lung cancer: the PLUS multicentre randomised trial. Lancet. 2002:359(9315):1388-92 Available from: https://www-sciencedirect-com.kuleuven.ezproxy.kuleuven.be/ science/article/pii/S0140673602083526.

15. Herder GJM, Kramer H, Hoekstra OS, Smit EF, Pruim J, van Tinteren $\mathrm{H}$, et al. Traditional versus up-front [18F] fluorodeoxyglucose-positron emission tomography staging of non-small-cell lung cancer: a Dutch cooperative randomized study. J Clin Oncol. 2006;24(12):1800-6 Available from: http:// ascopubs.org/doi/10.1200/JCO.2005.02.4695.

16. Onishi H, Shirato H, Nagata Y, Hiraoka M, Fujino M, Gomi K, et al. Hypofractionated Stereotactic Radiotherapy (HypoFXSRT) for Stage I Nonsmall Cell Lung Cancer: Updated Results of 257 Patients in a Japanese Multi-institutional Study. J Thorac Oncol [Internet]. 2007:2(7):S94-100 Available from: https://www-sciencedirect-com.kuleuven.ezproxy.kuleuven. be/science/article/pii/S1556086415325387.

17. Prescribing, Reording, and Reporting of Stereotactic Treatments with Small Photon Beams. Journal of the ICRU. ICRU Report 91. 2014;14:41.

18. Huang K, Senthi S, Palma DA, Spoelstra FOB, Warner A, Slotman BJ, et al. High-risk $C T$ features for detection of local recurrence after stereotactic ablative radiotherapy for lung cancer. Radiother Oncol [Internet]. 2013;109: 51-7 Available from: https://www.thegreenjournal.com/article/S01678140(13)00334-4/pdf.

19. Huang K, Dahele M, Senan S, Guckenberger M, Rodrigues GB, Ward A, et al. Radiographic changes after lung stereotactic ablative radiotherapy (SABR) â $€$ Can we distinguish recurrence from fibrosis? A systematic review of the literature. Radiother Oncol [Internet]. 2012;102:335-42 Available from: https://www.thegreenjournal.com/article/S0167-8140(11)00758-4/pdf.

20. Videtic GMM, Donington J, Giuliani M, Heinzerling J, Karas TZ, Kelsey CR, et al. Stereotactic body radiation therapy for early-stage non-small cell lung cancer: executive summary of an ASTRO evidence-based guideline. Pract Radiat Oncol. 2017;7(5):295-301 Available from: http://www.ncbi.nlm.nih. gov/pubmed/28596092.

21. Guckenberger M, Andratschke N, Dieckmann K, Hoogeman MS, Hoyer M, Hurkmans C, et al. ESTRO ACROP consensus guideline on implementation and practice of stereotactic body radiotherapy for peripherally located early stage non-small cell lung cancer. Radiother Oncol. 2017;124(1):11-7 Available from: https://www-sciencedirect-com.kuleuven.ezproxy.kuleuven. be/science/article/pii/S0167814017303766

\section{Publisher's Note}

Springer Nature remains neutral with regard to jurisdictional claims in published maps and institutional affiliations.

Ready to submit your research? Choose BMC and benefit from:

- fast, convenient online submission

- thorough peer review by experienced researchers in your field

- rapid publication on acceptance

- support for research data, including large and complex data types

- gold Open Access which fosters wider collaboration and increased citations

- maximum visibility for your research: over $100 \mathrm{M}$ website views per year

At $\mathrm{BMC}$, research is always in progress.

Learn more biomedcentral.com/submissions 